\title{
NOTAS SOBRE LA VIVIENDA RURAL EN ASTURIAS ENTRE LOS SIGLOS XIX y XX A TRAVÉS DE LAS TOPOGRAFÍAS MÉDICAS NOTES ON RURAL HOUSING IN ASTURIAS BETWEEN THE $19^{\text {th }}$ AND $20^{\text {th }}$ CENTURIES THROUGH MEDICAL TOPOGRAPHIES
}

Santiago Rodríguez Pérez* Universidad de Oviedo

\section{Resumen}

Las topografías médicas son trabajos en los que se estudian las condiciones ambientales y materiales de un territorio, con el objetivo de realizar acciones preventivas para mejorar la sanidad y la higiene públicas. En ellas, además de cuestiones sanitarias, se analiza también la geografía, clima, fauna y flora, urbanismo, demografía, economía, historia, etc. Este género de literatura científica, que tuvo su apogeo a finales del siglo XIX y principios del XX, es una fuente de interés para la investigación histórica. En el caso asturiano además resulta excepcional, ya que se realizaron más de cincuenta trabajos que cubren buena parte del territorio de la comunidad. A partir de los datos que proporcionan sobre las condiciones de vida en el medio rural, ofrecemos una breve síntesis de la situación del hábitat doméstico, sus problemas y transformaciones en las primeras décadas del siglo XX.

Palabras clave: arquitectura vernácula, Asturias, higienismo, vivienda popular, higiene doméstica

\section{Abstract}

Medical topographies are works studying the environmental and material conditions of a territory aiming to take preventive action in order to improve public health and hygiene. Aside from health matters, the area's geography, climate, fauna and flora, urbanism, demographics, economy, history, etc. are also considered in these works. This scientific literary genre flourished in the late 19th and early 20 th centuries, and is a very compelling source of historical knowledge. Furthermore, the case of Asturias is exceptional, since over fifty works covering much of the region's territory were written. Using their data on living conditions in rural areas as a starting point, we offer a brief overview of conditions in rural environments, their problems and transformations in the first decades of the 20th century.

Keywords: vernacular architecture, Asturias, hygienism, folk housing, domestic hygiene

\section{Introducción}


En este trabajo se realiza una breve contribución al estudio de la situación de la vivienda en el medio rural asturiano y sus transformaciones entre finales del siglo XIX y principios del XX a través de los datos que proporcionan las topografías médicas. El espacio doméstico de las clases populares ha sido objeto de numerosas investigaciones en los últimos años tanto a nivel estatal como regional, destacando las monografías sobre la vivienda obrera ${ }^{1}$. En menor medida, también se han realizado estudios acerca de las transformaciones urbanísticas y de las construcciones rurales desde principios del siglo $\mathrm{XX}^{2}$ con diferentes enfoques.

Las topografías médicas son un género de literatura científica cuyos antecedentes se remontan a la Ilustración, y que se engloban dentro del higienismo. En esencia, según esta corriente de pensamiento, el medio ambiente y el entorno social tendrían una importante influencia sobre el desarrollo de las enfermedades, por lo que la salud estaría estrechamente vinculada a las condiciones de vida de las poblaciones. Por ello, se consideraba que un estudio pormenorizado de la situación sanitaria en un entorno geográfico concreto permitiría detectar problemas y localizar focos de insalubridad. En consecuencia, podrían aplicarse medidas correctivas que mejorasen la calidad de vida y la sanidad de las poblaciones afectadas ${ }^{3}$.

En este contexto surgen las llamadas topografías o geografías médicas, cuyo auge en España se produce entre mediados del siglo XIX y las primeras décadas del s. XX. Se trata de estudios originales realizados por médicos cuyo objetivo principal es conocer el estado sanitario de una población, estudiando las patologías más características, su origen y su diagnóstico ${ }^{4}$. En estos trabajos, se realiza una descripción detallada de un área geográfica concreta, generalmente un municipio o comarca. Su estructura suele ser bastante homogénea, aunque puede haber variaciones, y en ellas encontramos apartados dedicados a la historia, geografía, geología, clima, hidrología, flora y fauna, urbanismo y vivienda, demografía, alimentación, a puntes de carácter antropológico y cultural, economía, trabajo y modos de vida, así como un análisis de las principales patologías. En ocasiones, también se aportan apuntes de etnografía y folclore, lingüística, etc. Finalmente, tras analizar todos los aspectos del medio, concluyen con una serie medidas correctivas, de policía sanitaria y mejora de la salud pública. Sobre las topografías médicas existe una nutrida bibliografía, como las publicaciones de Urteaga, y Casco Solís ${ }^{5}$, por lo que nos remitimos a trabajos especializados.

\section{Las topografías médicas en Asturias}

El caso asturiano resulta excepcional, ya que este tipo de estudios tuvo aquí un notable desarrollo ${ }^{6}$, siendo una de las provincias españolas con mayor número de obras. El pionero fue Gaspar Casal y su obra póstuma Historia Natural y Médica del Principado de Asturias (1762), a la que seguirían a mediados del siglo XIX los trabajos de Higinio del Campo (1847) ${ }^{7}$. Pero el auge de las topografías realizadas sobre términos municipales se produce a partir de 1884. La explicación se debe al legado del médico Faustino García Roel, quien a su muerte en 1895, cedió parte de su herencia a la Real Academia Nacional de Medicina para la creación de una fundación que premiase 
estudios médico-topográficos de términos municipales asturianos $\mathrm{y}$ madrileños. Esto supuso el inicio de la elaboración de topografías médicas por concejos de Asturias, enviadas por médicos locales para participar en el premio "Roel". Las memorias premiadas fueron publicadas y del resto se conservan los manuscritos en la biblioteca de la Academia.

Dado su carácter excepcional como fuente de información, las topografías se han utilizado en trabajos de carácter histórico ${ }^{8}$, geográfico ${ }^{9}$, historia de la medicina $^{10}$, historia de la maternidad ${ }^{11}$, geología ${ }^{12}$, o condiciones de vida de la clase obrera $^{13}$, entre otros. Pero también aportan informaciones sobre la situación del medio rural asturiano, el campesinado y su hábitat doméstico. En este sentido, sus observaciones resultan de especial interés, puesto que, debido a su profesión, tratan con asiduidad a los aldeanos y son testigos directos de su vida cotidiana, accediendo al interior de las viviendas en las visitas médicas (asisten partos, a enfermos y moribundos, etc.). En palabras de Fernán Pérez "el médico conoce mejor que nadie las necesidades de los pueblos, sabe en qué estado están los caminos, las fuentes, los ríos, etc. etc. [sic]; sin ningún trabajo irá señalando y corrigiendo los defectos que encuentre" $" 14$.

En Asturias, se han localizado hasta la fecha 51 topografías médicas ${ }^{15}$, pero el nivel de calidad de los datos que ofrecen es muy variable. Para el objeto de nuestro estudio, hay que indicar que no todas aportan referencias sobre la vivienda rural, y en algunas son muy exiguas. En otros casos, el esquema y los contenidos están reelaborados a partir de otras topografías publicadas en la época, como ha señalado Germán Ojeda, por lo que se repiten las mismas generalidades ${ }^{16}$. Sin embargo, muchos de estos trabajos sobresalen por la cantidad y la calidad de la información que proporcionan, incluyendo descripciones minuciosas de la casa en el área rural y los núcleos urbanos. Y aunque no se ocupen específicamente de las viviendas, la mayoría de ellas incluyen datos y descripciones del hábitat rural, la explotación del territorio (agricultura, ganadería, silvicultura, etc.), apuntes etnográficos y lingüísticos, folclore, etc.

\section{Otros estudios sobre la vivienda rural en el periodo de entresiglos}

Entre mediados y finales del siglo XIX, en el contexto de la incipiente industrialización, surge en Europa una preocupación por las condiciones de miseria y pobreza del alojamiento de las clases populares. Probablemente, los médicos higienistas fueron el sector más importante en iniciar de forma masiva la denuncia de la situación de las condiciones de vida de la clase obrera. Junto a ellos, ingenieros y arquitectos también se dedicaron a extender en España las nuevas corrientes de vivienda y urbanismo, con el objetivo de mejorar los alojamientos de trabajadores. Estas denuncias trascendieron a la prensa escrita, y algunas personalidades de círculos reformistas se hicieron eco de estas necesidades ${ }^{17}$.

Es también a finales del s. XIX cuando se produce en España el incipiente desarrollo de los estudios de folclore y antropología, así como el inicio de los estudios sobre la arquitectura vernácula por parte de arquitectos 
y etnógrafos ${ }^{18}$, con los trabajos de Lampérez y Romea, Torres Balbás, Anasagasti, García Mercadal, etc. En Asturias, los primeros estudios de carácter científico acerca de etnografía y cultura popular se realizan a finales del s. XIX ${ }^{19}$. Específicamente sobre la casa tradicional, se recoge una síntesis en el capítulo "De Vita et moribus..." del libro Asturias, de Bellmunt y Canella (1900). También hay que destacar las monografías (inéditas hasta fechas recientes) de Florentino Martínez Torner (Las construcciones rurales de Asturias, 1917) o Purificación Viyao (Datos antropo-etnográficos de la parte oriental de Asturias, 1920) ${ }^{20}$.

Algunos investigadores, como Arias González ${ }^{21}$, han hecho hincapié en la visión idealizada de la vivienda popular que se estaba gestando en este momento. Así, Lili Litvak ${ }^{22}$ señala que a través de los movimientos regionalistas y las pinturas paisajísticas que se transmiten mediante las revistas ilustradas, se desarrolla una visión muy idealizada e idílica del medio rural español ${ }^{23}$. Según estos autores, los arquitectos también se centraron en el análisis y la divulgación de las arquitecturas más representativas de cada zona, a las que convirtieron en únicas y características de un espacio, pero ocultando en cierto modo las condiciones de vida miserables de sus pobladores ${ }^{24}$. No obstante, aunque exista cierta idealización como indica Arias González, muchos de los trabajos que hemos consultado al respecto no son ajenos a los problemas de salubridad y las condiciones de miseria de sus habitantes. Evidentemente, estas carencias no eximen a estas construcciones de valor histórico, cultural y arquitectónico, lo que las convirtió en objeto de estudio de la antropología y la arquitectura. Aunque con la llegada de la industrialización pasaron a ser despreciadas como "infravivienda", es preciso comprenderlas en su contexto histórico y cultural. La arquitectura vernácula, popular, o tradicional proporciona una solución constructiva adaptada al medio y a los condicionantes geográficos, económicos y sociales. Buena prueba de esta capacidad de adaptación es que muchas de estas arquitecturas aún hoy siguen cumpliendo su función doméstica (obviamente habilitadas para los requerimientos higiénicos y las necesidades actuales). El inicio de esta transformación se encuentra en el primer tercio del s. XX, y precisamente una de las causas fue la labor de los médicos higienistas.

\section{La vivienda rural en Asturias a finales del s. XIX a través de las topografías médicas}

En 1847, en su obra Estudios sobre la pelagra (uno de los primeros textos del género en Asturias), Higinio del Campo señalaba las deficiencias de la habitación rural:

"Habitan, generalmente hablando, en casas pequeñas y aglomerados en los dormitorios, por lo común mal ventilados; otros, más pobres, se construyen miserables chozas, en las que duermen en amigable compañía con los ganados y demás animales domésticos. Sus camas se componen de jergones henchidos de hoja seca de maíz, y mantas encima, algunas tienen colchón y sábanas: en otras partes duermen en reunión en los pajares y sobre la ceniza en algunos parajes miserables y montuosos." 25 
En 1884, Nicanor Muñiz Prada, en la topografía de Mieres, describe así las viviendas del entorno:

"[...] la generalidad de las casas són (sic) sólo de piso terreno sin entarimado, arrimadas á la montaña por falta material de espacio en la parte llana de sus valles, sin más distribución que la de dos departamentos, la cocina y el dormitorio; formando en ocasiones una sola pieza, sin enlucido en sus paredes, con falta de buena mezcla ó mortero, con materiales tan higroscópicos como la arenisca y pizarra carbonosas, única piedra de construcción en este concejo, por no existir otra. Las paredes interiores están ennegrecidas por el humo y recubiertas de hollín; debido á la falta de chimeneas y á la costumbre general en las casas de los labradores de poner sobre el hogar, á dos metros de altura próximamente, el sardo, que no es otra cosa que un tendedero de madera, con el objeto de secar frutos: como las castañas, maiz, habas, etc., lo que impide por completo el paso del humo, saliendo al exterior por las puertas y ventanas, después de haber recorrido toda la vivienda."26

Estas construcciones, calificadas de "antiguas" ${ }^{27}$ en las topografías médicas, son el tipo común de vivienda popular en Asturias hasta finales del s. XIX. Frecuentemente se trata de casas terrenas (fig. 1), que en el caso de labradores pudientes, pueden tener dos pisos. En todas las topografías que abordan la casa rural, las descripciones suelen coincidir en los aspectos principales, si bien recogen también algunas particularidades de la arquitectura local. El modelo "arcaico" de casa tradicional descrito con mayor frecuencia lo resumimos a continuación: se trata de una vivienda de planta cuadrangular, generalmente de planta baja, terrena. En ocasiones tiene un piso, según la capacidad económica de los propietarios. Las paredes se realizan en mampostería de piedra y argamasa de barro, y por lo general, no se revocan con cal ni al interior ni al exterior. El tejado suele ser a tejavana, sin desván y con la armadura de cubierta vista. En el interior, se dividen en dos ámbitos diferenciados: la cuadra y el espacio habitado. Dentro del espacio doméstico encontramos el cuarto principal, la cocina. Habitualmente tiene el suelo de tierra pisada o enlosado, y se cocina con el fuego en el suelo. Carece de salida de humo, y éste se evacúa entre las tejas o losas del tejado, o a través de ventanucos, por lo que las paredes están ennegrecidas de hollín. En este espacio se hace la vida común, y anexo a ella se encuentran los cuartos y almacenes de aperos en las casas terrenas, mientras que en las de una planta, los dormitorios se encuentran en el piso superior. Las divisiones internas, cuando las hay, son de tablones de madera o de varas entretejidas ${ }^{28}$, pero por lo general, no suele haber divisiones entre cuartos, por lo que no es infrecuente que los miembros de la familia duerman juntos. La cuadra está en la planta baja, separada por una pared de mampostería o un tabique de madera. La mayoría no poseen retrete, y si lo tienen, varía desde un agujero en el piso sobre la cuadra, o un hueco o pequeño cuarto con salida al exterior. Por lo general, las ventanas son escasas y de tamaño reducido, sin vidrios y cerradas con postigos de madera. El alumbrado nocturno se realiza con lámparas de aceite. 


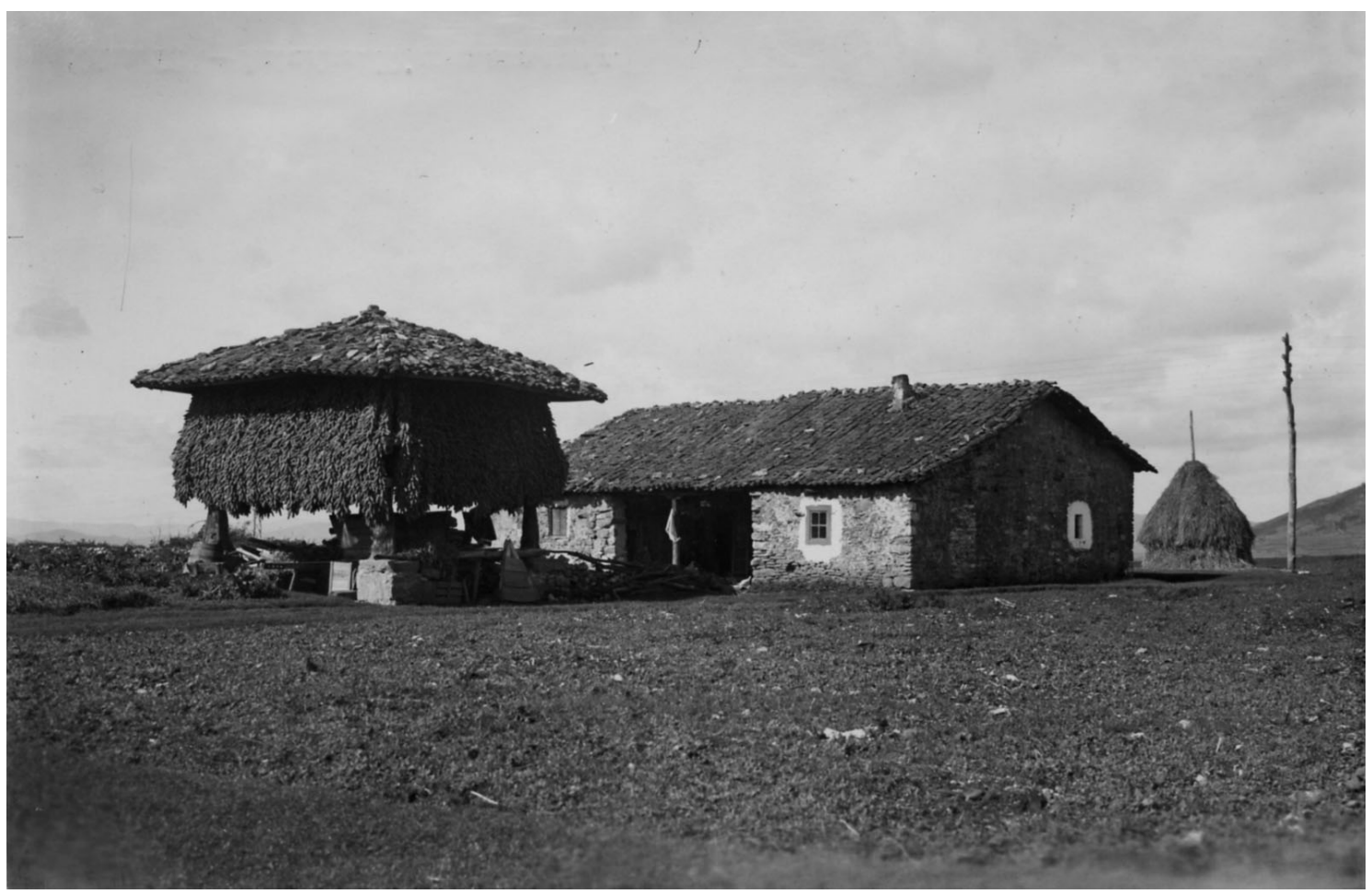

Fig. 1. Casa campesina, hórreo y vara de hierba. Celestino Collada, ca. 1930. Fuente: Muséu del Pueblu d'Asturies.

Las descripciones de la vivienda se centran por lo general en los aspectos relacionados con la higiene, y prestan muy poca atención a las particularidades arquitectónicas y tipológicas de los edificios. No obstante, algunos autores como José de Villalaín analizan y distinguen diversos tipos de viviendas en función de los recursos económicos de los propietarios y su clase social: caseros o colonos (casas terrenas, pobres y sencillas); labradores (de planta baja pero con algunas comodidades, como el piso de madera en los cuartos), labradores ricos (una planta alta con dormitorios, mayores medidas higiénicas, presencia de hórreo o panera), los chalés de "americanos" (casas de construcción moderna), o palacios y casonas (algunos de ellos habilitados con ciertas comodidades).

En varias topografías médicas, como las de Gijón, Avilés, Soto del Barco, Tapia, etc., se describen los enseres y el ajuar doméstico, y en algunos casos encontramos apuntes sobre la decoración. Jove y Canella detalla de esta forma el mobiliario de las casas de Sobrescobio (1932):

"El moblaje, escaso, se compone de lo puramente preciso y es, en general, pobre, como cumple a gente campesina, cuya vida está informada por una gran sencillez. El menaje de cocina consiste en la masera, que sirve para amasar el pan; ésta se usa como mesa de comedor y es reservorio del pan y restos aprovechables de las comidas; el vasar, pequeño armario, donde se encierra la humilde vajilla, y la espetera, de donde penden los utesilios [sic] para cocinar y los recipientes de agua. Por cierto que la nota aguda de esta habitación suele darla este último mueble, por la tradicional importancia que se da a la limpieza de los objetos que sustenta (potes, peroles, ferradas, etc., aquéllos, de cobre, y ésta, de madera, pero con anchas abrazaderas 
de hierro) y que con motivo de esa limpieza cuidadosa brillan estrepitosamente.

El principal mueble de las habitaciones suele ser el arca, que cumple las funciones de armario: suele ser de gran magnitud y era corriente que, a tono con su uso, fuera de esmerada confección, realzada con tallas y herrajes de verdadero gusto artístico; por ello, sin duda, va desapareciendo casi de modo absoluto, camino de las poblaciones, donde el gusto moderno las puso en moda y siendo actualmente substituidas por la vulgar cómoda. A esto, a alguna silla, a la cama vulgar, corrientemente de madera, y a la que se añade una pequeña mesa, queda reducido el mueblaje de la vivienda. Como elementos de adorno no suelen observarse más que alguna estampa religiosa, algún cromo de asuntos variados, algunos floreros de vidrio coloreado y las típicas esferas de la misma substancia y de color plateado y dispuesto todo ello con más o menos gusto."29

Junto a la descripción de la vivienda, y como apunte de carácter etnográfico, algunos autores incluyen breves reseñas sobre los hórreos y paneras. A diferencia de la casa, el hórreo suele ser retratado como un elemento pintoresco, resaltando su carácter utilitario y sus connotaciones etnográficas, antigüedad, etc. No obstante, en el relato de sus características suelen reiterar las descripciones del mismo realizadas por Jovellanos, Julio Vigón o Frankowski. También se alude a su uso ocasional como dormitorio, señalando que resulta un cuarto ventilado y limpio por sus características.

\section{Problemas de salubridad. La vivienda como foco de enfermedad.}

La situación de la mayoría de las viviendas rurales distaba mucho de reunir unas condiciones mínimas de habitabilidad para los estándares modernos, por lo que todos los médicos denuncian sistemáticamente estas circunstancias. En este sentido, el diagnóstico que realiza la topografía de Caso (1945), resulta acertado:

"Es indudable que las causas higiénicas influyen extraordinariamente en la mortalidad, sobre todo de algunas formas de enfermedad, y entre todas destaca la habitación y los alrededores de la casa, la carencia de ventilación, la promiscuidad, la mescolanza con los animales, la cercanía del estiércol con las innumerables moscas que de allí salen, hacen que la tuberculosis sea tan extendida, en cualquiera de sus formas [...]. Duermen con los padres o hermanos enfermos, sea cual sea la enfermedad que padezcan, la ventilación deficiente hace que los niños adquieran con gran facilidad bronquitis." 30

Ciertamente, las situaciones que detallan las diferentes topografías respecto de las condiciones de higiene y salubridad de las viviendas no eran precisamente las más adecuadas. Respecto a su ubicación, las denuncias se enfocan en la arbitrariedad de la ubicación (aunque se reconoce que no siempre es posible elegir el sitio). Muchas están adosadas a las laderas, por lo que presentan problemas de humedad y no siempre en lugares soleados y bien aireados ${ }^{31}$. 
En el interior de la casa, el primer problema que apuntan es la mala ventilación. Los vanos son escasos y pequeños, solución habitual en la arquitectura vernácula en búsqueda de un mayor aislamiento (el uso del vidrio no se populariza hasta finales del siglo XIX). A ojos del médico, esto no facilita la renovación del aire al interior, y se ve agravado por la falta de costumbre de ventilar. Villalaín (Avilés, 1913) señala "el horror a la ventilación, por miedo a las corrientes de aire"32. Esta preocupación es común en todos los textos y es una de las principales recomendaciones para limpiar los ambientes infectos y renovar el aire. También llaman la atención sobre la mala evacuación de los humos en las cocinas de llar, en las casas que no disponen de chimenea o campana, saliendo el humo entre las tejas o por pequeños huecos. Las paredes están cubiertas de hollín, y se consume el oxígeno en el interior de la cocina (fig. 2).

Otro de los problemas que se destacan es la ausencia de divisiones internas y de tabiques entre los cuartos de dormitorio ${ }^{33}$. El hecho de que varias personas de una familia compartan la misma estancia para dormir, además de podría comportar graves problemas de moralidad, dificulta el control de las enfermedades infecciosas, que se propagan rápidamente entre individuos mal aislados.

La ubicación de las cuadras es otro problema de difícil solución. Los establos ocupan la mitad del espacio edificado en las casas terrenas y una buena parte de la planta baja en las de un piso. La convivencia estrecha con los animales (vacas, cerdos y gallinas) bajo un mismo techo, agrava la suciedad y los olores en el interior de la vivienda, así como la presencia continua de moscas. Los animales depositan sus deyecciones en ella, por lo que el cucho o estiércol debe retirarse a diario. La costumbre tradicional de sacar el cucho de la cuadra y apilarlo cerca de la puerta o en las inmediaciones de la vivienda es denunciada sistemáticamente en todas las topografías, ya que se considera muy insalubre por las emanaciones y un caldo de cultivo para bacterias ${ }^{34}$. La lluvia contribuye a esparcirlo, formando lodazales, y en ocasiones llega a los caminos, donde mezclado con el barro forma un cieno por el que transitan animales y personas. También preocupan las filtraciones de los lixiviados hacia los pozos de agua potable ${ }^{35}$. Esto se agrava por otra costumbre, provocada por la necesidad de fertilizantes: en los caminos y en espacios próximos a la vivienda, y en lugares encharcados, se depositan desechos (tallos de maíz, matorral y rozo, así como desperdicios en general y restos de comidas, junto a las aguas sucias de los albañales) para que con el tránsito se descompongan formando materia orgánica que añadir al estiércol $^{36}$. A pesar de ello, reconocen que eliminar esta práctica es muy difícil, ya que se necesita todo el fertilizante disponible para las tierras. En algunas topografías se aconseja la construcción de estercoleros cubiertos e impermeables, que impidan los olores y la lixiviación de sus componentes por efecto de las lluvias, así como las filtraciones, lo que repercutiría en una mayor calidad del abono.

Finalmente, otra de las quejas comunes es la ausencia de retretes y aseos en las viviendas, prácticamente en la mayoría de las casas antiguas, y en algunas de las que se están construyendo en este momento. Por lo general, los campesinos realizan sus necesidades al aire libre o en el interior de las 
cuadras. Los retretes, cuando existen, consisten en pequeños cuartos o aberturas que comunican con la cuadra o a la parte exterior de la casa, donde se acumulan formando pilas, si no existe un pozo negro que recoja las excretas.

Sin duda, visto con perspectiva, el panorama que describen las topografías médicas con respecto a la vivienda rural no resulta nada agradable, y conforma una visión muy poco idílica de las condiciones de vida en el campo. La falta de salubridad de las viviendas preocupa a los médicos higienistas y provoca quejas reiteradas en todas las topografías. Además, en opinión de los higienistas, estas circunstancias tienen una repercusión clara en la salud de los habitantes, dando pie a situaciones como la denunciada por el autor anónimo de la de Lena (1907):

"iCuántas veces al cumplir con nuestra misión nos encontramos con un desdichado enfermo tendido sobre miserable y sucio lecho al par del fuego envuelto en irrespirable atmósfera de humo que le presta una cocina de leña desprovista de chimenea y rodeándole un enjambre de animales domésticos que mancomunadamente con las personas tienen allí su albergue!"37

La casa, según su criterio, puede favorecer la aparición de enfermedades o ser foco de contagio de las mismas. De hecho, cuando se producen brotes infecciosos, como el tifus o el sarampión, es muy difícil controlarlos, tanto por la falta de hábitos de higiene, como por la propia configuración de las viviendas, con cuartos en los que duermen varias personas, sin separaciones internas y difíciles de desinfectar ${ }^{38}$. Así, Portolá denuncia la situación en Ponga (1915):

"La habitación del enfermo debe estar bien ventilada, sin temor á los catarros. Una arraigada preocupación reina aquí, y es la referente al temor á la ventilación y aireación del cuarto del paciente. Cerrada la puerta y la ventana (ésta á veces no la hay) pronto el aire se hace irrespirable, y es causa de serio perjuicio y grave obstáculo para la buena evolución de la enfermedad y para las condiciones de resistencia orgánica del enfermo.

[...] En la mayor parte de las casas de los pueblos de este concejo es muy difícil practicar el aislamiento, porque son casas habitadas por modestos labradores, muy reducidas y con pocas habitaciones; por eso es frecuente, en tiempos de pandemia sarampionosa, ver dos ó tres niños enfermos en una misma cama, ó bien á los que están aún sanos dormir en el mismo cuarto que los que padecen la epidemia." ${ }^{39}$

Obviamente, la vivienda no es la única causa de todos sus males. Existen otros factores que también se recogen en las topografías. La pobreza, y en general la depauperización en la que vive buena parte del campesinado (muchos de ellos son colonos rentistas) tiene sus consecuencias en una mala alimentación, acceso a ropa, bienes y servicios básicos o medicinas, etc. A ello se suma la escasa escolarización de la población. Influye también la escasez de inversiones y mejoras en el medio rural, como las comunicaciones, el abastecimiento de aguas, etc. 
La situación higiénica de la vivienda de las clases populares era un problema común a todo Europa. Muchas de las obras sobre higiene que se publican a lo largo del s. XIX en España, incluyen capítulos específicos dedicados a la vivienda de los trabajadores, su situación y posibilidades de mejora. En ellas se recogen propuestas para el saneamiento y la mejora de las condiciones de salubridad, desde materiales de construcción, ventilación, calefacción, limpieza, evacuación de aguas, etc. En algunos de estos trabajos también encontramos apartados específicos dedicados a los espacios rurales. Podríamos citar entre otras la Higiene Industrial (1854) ${ }^{40}$ de Pere Felipe Monlau, las Nociones de Higiene, de Nicanor Muñiz Prada $(1885)^{41}$, Higiene Popular, de Ambrosio Rodríguez (1902) (que incluye un breve apartado dedicado a los labradores), ${ }^{42}$ El presupuesto de una familia obrera, de Úbeda y Correal (1902) ${ }^{43}$, u Hogar y Patria, de Aurelio de Llano (1906) ${ }^{44}$, en la que se propone un proyecto-modelo para construcción de viviendas obreras. Avanzado el siglo XX, en Saneamiento e Higienización de España (1920) ${ }^{45}$, Gómez de Membrillera dedica un capítulo específico a la higiene de la vivienda rural, donde nos encontramos de nuevo con los problemas ya referidos en las topografías médicas (casas antiguas y poco limpias; convivencia de animales y personas bajo el mismo techo; dormitorios de uso común con enseres pobres; ausencia de ventilación y de luz; ausencia de retretes, estercoleros en las inmediaciones de las viviendas; falta de educación higiénica entre los habitantes del campo; carencia de abastecimiento de aguas, etc.).

Las topografías médicas también aportan propuestas para la mejora de la higiene doméstica. Como ejemplo, cabría citar a Vilar Ferrán, que en la de Cabrales (1921) prescribe las siguientes medidas:

"Higienización de viviendas-De cumplir lo estatuido en la Real orden de 12 de Octubre de 1910 referente a construcciones, tendrían que arrasarse casi todas las aldeas de Cabrales - y la mayoría de las de España- para reedificarlas luego con arreglo a ella.

Pero como esto no es posible hacerlo con la rapidez que la higiene demanda, podría con el tiempo conseguirse el mismo resultado si las autoridades municipales de los pueblos rurales tuvieran energía y constancia para hacer cumplir los reglamentos de higiene municipal sobre edificaciones.

En este Concejo es de imprescindible necesidad y de urgencia tomar medidas serias respecto a las viviendas. Las actuales, de poca capacidad, sin luz ni ventilación, y, desde luego, sucias, son las causantes de que la tuberculosis origine tantas víctimas. Otras enfermedades de la localidad obedecen — según ya expusimos - a la misma causa.

Debe, pues, prohibirse en absoluto toda nueva edificación que no reúna condiciones apropiadas para vivir el hombre; espacio suficiente para asegurar ocho metros cúbicos de aire, por persona, en cada dormitorio y que éstos tengan ventilación directa al exterior; aberturas para que pueda entrar la luz solar hasta el último rincón de la casa, y que permitan su perfecta ventilación, etc. etc. - $-\mathrm{y}$ no consentir ninguna 
reparación en las casas viejas que no sea a base de mejorar sus condiciones higiénicas.

De este modo podría lograrse la transformación, en un tiempo relativamente corto, de las construcciones malas y antiguas por otras sanas. El estado ruinoso de algunas y la poca solidez de todas abreviarán este resultado." 46

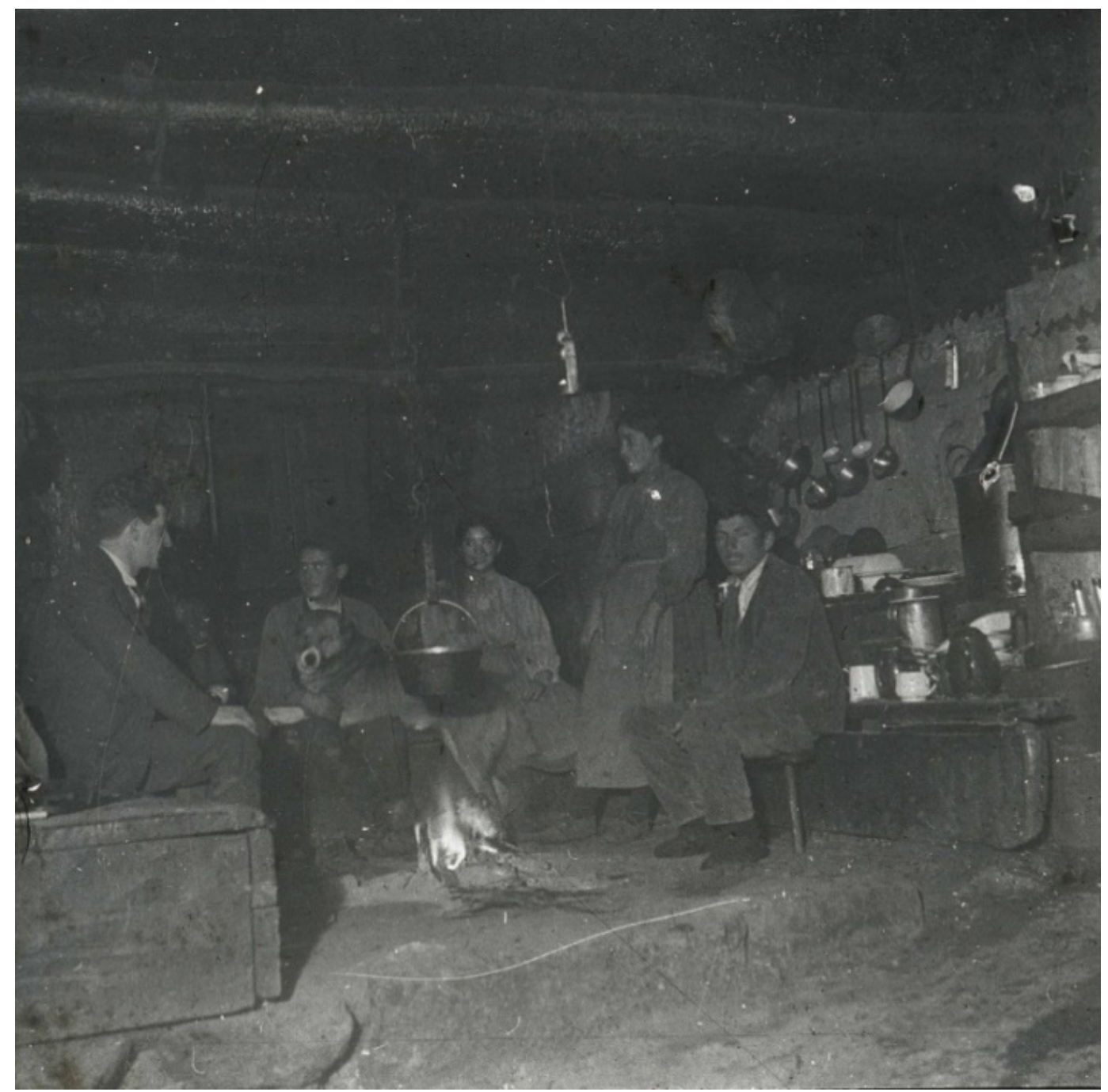

Fig. 2. "Cocina en Puerto del Pontón". Celso Gómez Argüelles. Amieva, 3 de marzo de 1919. Fuente: Muséu del Pueblu d'Asturies.

En todas ellas se insiste en varios aspectos: mayor educación higiénica de los habitantes; higienizar las viviendas que aún no lo estén, separando de ellas las cuadras de vacas, cerdos y los gallineros; blanqueo interior y exterior con cal, limpieza y barrido frecuentes; prohibir el depósito de estiércol y basuras cerca de las casas; completar las redes de alcantarillado y suprimir pozos negros o mantenerlos limpios; prohibición de verter detritus y basuras en las inmediaciones de las viviendas y en las vías públicas ${ }^{47}$. 


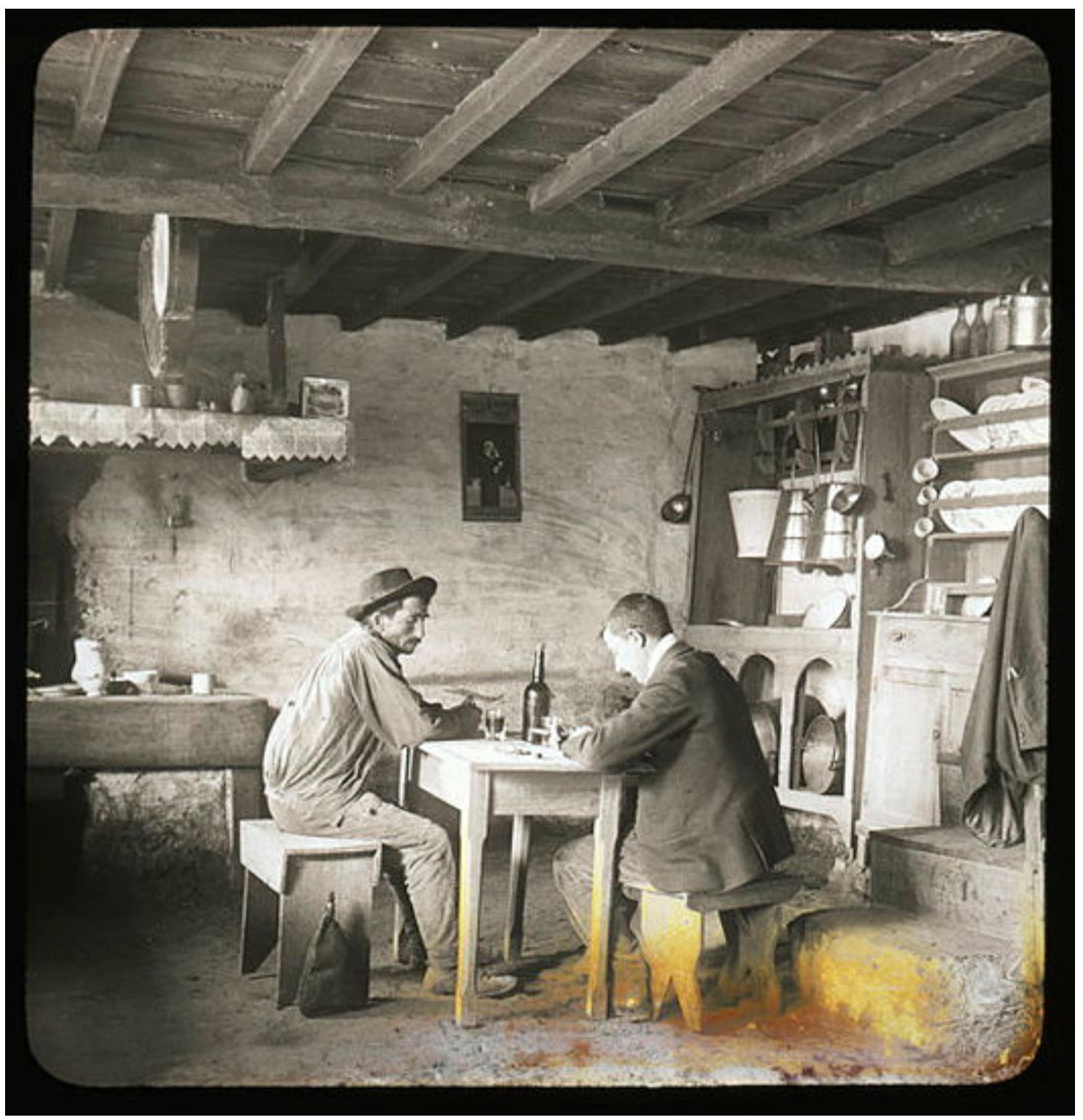

Fig. 3. "Cerrando el trato". Llanera, ca. 1910. Fotografía de Gerardo Bustillo (1870-1919) Fuente: Muséu del Pueblu d'Asturies. En esta imagen se aprecian algunos cambios. El llar es alto, decorado con papel recortado. Hay una pequeña mesa con bancos. El vasar rebosa de platos, tazas y vajilla de loza blanca. En el espeteru, junto a las ferradas de madera, los canxilones y calderas de cobre, encontramos nuevos enseres de origen industrial, como los calderos de hierro esmaltado.

\section{La transformación de la vivienda tradicional}

A finales del siglo XIX se están produciendo una serie de transformaciones en el medio rural que afectarán también a la vivienda tradicional. Como ya ha señalado Juaco López ${ }^{48}$, el campo asturiano estaba experimentando cambios considerables, en especial el localizado en la zona central y más próximo a las ciudades. El crecimiento urbano aumentó la demanda de la producción agraria, y la mejora de las vías de comunicación (ferrocarriles y puertos) favoreció el abaratamiento de los cereales, lo que 
permitió la expansión de la ganadería de leche. Las topografías se hacen eco de este progreso rural, como la de Carreño, donde se describe el desarrollo de la producción agrícola, el aumento de la cabaña ganadera y la introducción de nuevas razas, el desarrollo de la industria sidrera, etc. ${ }^{49}$ Las expectativas del campesinado cambiaron sustancialmente, y esto se traduce en la mejora de las explotaciones y de las condiciones de vida. En este momento, empiezan a construirse amplias viviendas de planta baja y un piso, con paneras de gran tamaño para almacenar las cosechas, y con las cuadras y tenadas fuera de las viviendas. Así, vemos que en Oviedo (1915):

"No todas las viviendas rurales son como las que dejamos apuntadas; éstas son las típicas, las primitivas de nuestros labradores, que hoy ya van, poco á poco, modificándose con ventanas de cristales, cocinas con chimenea; y cuando los recursos les ayudan, levantan una solana ó un piso con corredor."50

Las ideas higienistas son propugnadas desde el ámbito sanitario, aplicadas en las nuevas construcciones por arquitectos e ingenieros, e impulsadas por la legislación en materia sanitaria desde el Estado. Paulatinamente, estas mejoras en la construcción van introduciéndose en las viejas caserías, pero lentamente y con variaciones entre comarcas. Las razones hay que buscarlas en la falta de recursos económicos. En buena medida, el campesinado seguía siendo colono de grandes propietarios de la aristocracia y la alta burguesía, con lo que se veía condenado a una subsistencia muy precaria y a mantener las viejas casas de una planta ${ }^{51}$. No obstante, en ocasiones se responsabiliza a los campesinos de su situación higiénica. En la topografía de Bimenes (1907), por ejemplo, se atribuyen sus males a la desidia, la ignorancia, la falta de moralidad o el alcoholismo:

"El espectáculo del exterior no causará envidia ciertamente al del interior de las casas; paredes negras, sin encalar y destilando humedad, forman la habitación en que todos los días el médico ha de ejercer su misión recordando las lindas descripciones de la morada ideal para un enfermo. La desidia que informa todos los actos de esta gente se traduce más claramente en la limpieza -mejor diría en la falta de limpieza- de la casa. Cuesta el mismo dinero construir una casa higiénica que una que no lo sea; á veces cuesta más esta; el gasto del blanqueo puede considerarse sin valor y da un aspecto tan alegre a la casa que bien merece el sacrificio de un rato de trabajo ya que los materiales pudieran tenerlos casi de balde." 52

Pero difícilmente se podría renovar y blanquear la vivienda, o construir una nueva, cuando su autor también denuncia en la misma topografía la miseria, la escasa y mala alimentación o la presencia de enfermedades como el raquitismo y el bocio. La situación de las viviendas es más bien consecuencia de las condiciones de pobreza del campesinado que de su propia ignorancia (lo cual revela también en ocasiones ciertos prejuicios sobre el campesino, como atrasado o falto de interés). Sin embargo, la "cuestión social" está presente, y los médicos son conscientes de ello: muchos campesinos difícilmente podrían permitirse el encalado de las casas, la compra de materiales de construcción modernos como azulejos y losetas, o la edificación de nuevos establos fuera del espacio doméstico. El propio Villalaín lo resume 
en la topografía de Avilés (1913), cuando dice que "si el obrero avilesino es sucio lo es por ser pobre"53. En otras topografías, sus autores reconocen las dificultades para hacer frente a costosas mejoras, como en Degaña (1913), donde "no pediremos tales medios, implantarlos en Degaña no sería posible por razones económicas fáciles de comprender" ${ }^{54}$. La visión del habitante del medio rural como alguien reacio a los cambios y las mejoras resulta sesgada. Es evidente que cuando la economía doméstica prospera, el campesino accede a la propiedad y dispone de cierto capital, también mejoran las condiciones materiales de vida. Por ejemplo, en el caso de Tapia de Casariego, si bien en fechas avanzadas (1932), la imagen de los labradores que se transmite es muy distinta:

"Es curioso, y lo hacemos constar con íntima satisfacción, que casi todos los vecinos son dueños de la mayor parte de la tierra que cultivan. Aquí no se conocen los caseríos a renta, ni las aparcerías; todo, afortunadamente, ha desaparecido, y sólo queda, rasgo que les honra y expresa su psicología, la propiedad individual. Tal vez sea éste el principal motivo de su constante laboriosidad, de su buen conocimiento de la agricultura y de su envidiable paciencia para el mejor cultivo." ${ }^{55}$

En consecuencia, la vivienda tapiega también es más grande, de varias plantas, con estancias amplias, luminosas y bien encaladas, con diferentes construcciones auxiliares (pajar, cabazo, etc.) y dispone de maquinaria agrícola moderna ${ }^{56}$.

Si bien los vecinos podrían realizar mejoras individuales en sus viviendas, no sin cierto esfuerzo y teniendo en cuenta las diferentes situaciones, hay algunas cuestiones que no dependen de la iniciativa particular. En la de Tapia (1932), Fernández señala respecto al estiércol que se acumula de los retretes en la villa debido a la ausencia de alcantarillado que "no es que agrade esta vida a nuestros tapiegos, gente culta y amante de la higiene; es que la necesidad les obliga, por carecer de otros medios de evacuación de sus desechos y necesariamente han de aprovechar el único posible." $" 57$

En este sentido, cabe destacar que la transformación no era solamente una cuestión individual de higiene doméstica, ventilación, viviendas con nuevos materiales, etc. En 1929, el gobierno encarga un informe sobre la vivienda rural, publicado por el Ministerio de Economía ${ }^{58}$. En el citado informe, resumido por Oyón Bañales $(1985)^{59}$, se observa que en los años 30 ya se estaba avanzando más allá de la propuesta de soluciones tipo para la vivienda higiénica de los campesinos. Estas mejoras no podrían ser efectivas sin solucionar otras cuestiones del urbanismo rural, tales como los caminos y accesos (lodazales en invierno, polvorientos en verano), abastecimiento y evacuación de aguas, educación escolar, etc. El problema de la vivienda no se limitaba a la iniciativa particular y a la construcción de edificios aireados, higiénicos y con separación entre personas y animales, sino que incluía otras necesidades que abarcaban el conjunto de los poblados y los servicios públicos de educación, asistencia y sanidad. En este sentido, será clave la intervención del Estado y el desarrollo de políticas de urbanismo en el medio rural, que se desarrollarán en la posguerra. 
En la transformación de los espacios domésticos rurales, influyó el crecimiento económico y el progreso material de las zonas próximas a núcleos urbanos o industriales, la acción de los médicos higienistas, o los intentos por aplicar los reglamentos y normativas de sanidad en la construcción desde los estamentos públicos. Pero quisiéramos destacar otros factores, señalados en las topografías médicas que también tuvieron cierto protagonismo en el cambio: la aportación de los "americanos" y, por otra, el papel femenino en estos cambios.

\section{Influencia de los "americanos" en la renovación doméstica}

En la mayoría de las topografías médicas se alude a la emigración a ultramar, muy elevada en algunos concejos, y el contacto que se mantiene con los lugares de origen. Y también se hacen eco precisamente del "elemento americano" ${ }^{60}$ como agente innovador en el medio rural. En efecto, los indianos financian numerosas obras, como escuelas, lavaderos, fuentes, caminos y carreteras, e introducen nuevas modas en la arquitectura y la construcción, como ya señalaron entre otros Juaco López ${ }^{61}$ o Fernández Riestra y Marcos Fernández ${ }^{62}$. Entre las nuevas ideas adquiridas en América, para los médicos higienistas destacan los hábitos de aseo y limpieza de los emigrantes retornados, que poco a poco van calando en el campesinado asturiano. Villalaín ${ }^{63}$ describe en la topografía de Avilés que "del mismo modo que de América venía dinero, venía también el cambio de las costumbres, y así como en otros terrenos que no son de nuestra incumbencia vinieron usos que mataron los tradicionales, en el nuestro vino el uso del aseo personal."

Evidentemente, esto también se traduce en la renovación de la arquitectura doméstica. En 1913, entre los tipos de vivienda en Avilés, Villalaín señala las "casas donde hay un americano"

"Unas son nuevas y cómodas. Otras son la renovación de la antigua casa paterna: son limpias y con buenos servicios higiénicos. En Asturias, el elemento americano es civilizador en todo, incluso en la propaganda de las buenas ventajas de la higiene. Otras casas de americano tienen «el cuarto». Se trata de familias pobres que esperan un hijo no muy rico, y antes de que éste llegue de Cuba le hacen una habitación adosada á la casa, blanqueada, tillada y amueblada modestamente; esto es «el cuarto», que contemplan con admiración los vecinos pobres, y hacen bien, porque de aquel cuarto y de su habitante han de salir provechosas enseñanzas de higiene personal, como son el uso del jabón y el aseo diario de la cara y el semanal de los pies, amén del frecuente cambio de ropa interior, entre otras cosas" ${ }^{65}$

En Carreño (1919), Villalaín señala que hay muchas "casas modestas modernas bastante higiénicas que por lo general pertenecen a americanos. Aunque suelen ser reducidas, tienen todo lo que la higiene pide", y son "limpias, bien pintadas y apañaditas, con lo que revelan que su dueño rodó por el mundo" ${ }^{66}$. Continúa añadiendo que:

"La higiene médica mejora con esas viviendas nuevecitas y simpáticas que salpican las laderas de los valles, y con esa nimiedad que es la "pastilla de jabón de olor" o el frasco de "agua florida" que viene de regalo 
a la novia o a la hermana lejanas, con la limpieza de que dan ejemplo las quintanas de los americanos, con el aseo en el vestir, con no oponerse a la vacunación, y con el relato de las atrocidades que en Cuba comete la Sanidad Pública con las que carecen de sentido higiénico: estos relatos cunden y valen" ${ }^{\circ 7}$.

Así, los capitales procedentes de América permiten la compra de tierras, remozar y mejorar las viejas casas paternas o construir nuevas viviendas, en las que se introducen materiales.

\section{El papel femenino como motor de transformación}

Quizás un aspecto menos estudiado es el papel ejercido por las mujeres en la transformación de la vivienda rural en Asturias. Dada la extensión de este trabajo, nos limitamos a realizar algunos apuntes sobre la intervención femenina en el espacio doméstico rural a partir de las noticias de las topografías médicas. En este sentido, sobre la evolución de concepto de domesticidad, y la feminización de los espacios domésticos, cabría señalar los trabajos de Gloria Franco Rubio ${ }^{68}$ y la obra colectiva coordinada por Beatriz Blasco Esquivias ${ }^{69}$.

En las topografías médicas elaboradas por José de Villalaín (Avilés, Castrillón, Carreño, Corvera, Soto del Barco, Illas, Luarca), se incide en el protagonismo femenino en la introducción de medidas higienistas y de limpieza doméstica. Villalaín lo atribuye en ocasiones, erróneamente y sin duda influido por los prejuicios de la época, al gusto femenino por el lujo, o a manías. Tampoco carece su opinión de cierta idealización de lo rural en muchos aspectos, lo que le lleva a distinguir entre el espíritu práctico de la campesina frente al amor por los caprichos de la obrera ${ }^{70}$. Pero, si obviamos este tipo de apreciaciones subjetivas, su descripción resalta claramente cómo las mujeres son un agente muy importante y poco reconocido en la introducción de medidas de higiene y mejora del ámbito doméstico. En la topografía de Corvera (1925), por ejemplo, señala que:

"Los dormitorios son limpios y muy fregoteados si en la familia hay mozas, y si no las hay son tan sucios como la cocina; pues hay que advertir ahora que en la aldea asturiana se desarrolló de hace pocos años a esta parte, una verdadera manía por tener cada moza la casa más limpia que la vecina. Antes, cuando no había esta manía saludable, las camas eran sucias y nidos de insectos. Ahora ocurre todo lo contrario, pues es rara la obrera de la aguja que no traiga a la aldea usos de las «casas de señores» donde trabaja; y quien dice la obrera de la aguja, dice también la mocina que lleva los productos del campo al mercado de Avilés, y la joven emparentada con "americanos", y otras que siempreal fin mujeres-sienten la tentación del lujo. Pero como el aldeano es un Sancho práctico, el amor al lujo de las hijas de la aldea, se encauza hacia lo que es práctico para vivir cómodamente, y así en esas casas pobres no se ven esos «botecitos de mudas» baratos que se hallan en las casas de las obreras, entre medias de seda y blusas de lo mismo: allí, al contrario, el espíritu del observador encuentra un descanso, harto de miserias de la vida, viendo las camas nuevas, las ropas blancas, el suelo fregado, y 
en un rincón la máquina de coser, pocas veces pagada a plazos, por obra de los amos de la casa, siempre previsores para una enfermedad u otro apuro de los corrientes en la vida de la aldea. La cocina sigue, a pesar de todo, siendo sucia, con el piso de tierra humedecido con agua de fregar, y a veces bien paseado hasta por las gallinas, que acuden pidiendo sus granos de maíz al ama de la casa atenta al glu glu del pote familiar. La cuadra suele tener comunicación con la cocina."71

Y en nota al pie, aclara:

"En otra clase de trabajos parecería ñoña esta observación del amor a la limpieza de las jóvenes de la aldea. En éste, de topografía médica, no creemos por completo inoportuno hacer resaltar el hecho aun a riesgo de parecer pueriles observando, porque es una gran verdad que entre la higiene doméstica de hace veinte años y la de ahora existe un hermoso abismo, obra de la generación femenina actual amiga del lujo: de ese lujo práctico que llaman confort." 72

Obviamente, en su opinión pesan demasiado los prejuicios sobre lo femenino, pero de forma indirecta, nos proporciona algunos detalles sobre el papel de las mujeres jóvenes en la modernización de los interiores domésticos rurales, con la introducción de nuevos hábitos de limpieza, aseo personal e higiene. También introducen el gusto estético por la decoración, cambio de muebles, etc. En la topografía de Soto del Barco (1932), Villalaín resalta que "en las casas donde no hay muchachas podemos notar su ausencia en lo poco limpio del tillado, en la falta del "papel de cocina", en que la cocina "económica" se enciende, o por lo menos se limpia, pocas veces." A ellas se debe también la renovación del mobiliario, incorporando muebles modernos de pino, o el gusto por la higiene doméstica y personal, que contrasta claramente con la situación descrita en otras topografías anteriores:

"En las casas donde hay muchachas jóvenes hay un exceso-si en esto cabe exceso-de limpieza. [...] Pues bien, lector: pidamos a esta moza (ya que suponemos estar dentro de su cocina) un vaso de agua, y veremos que esclaria el vaso en agua tres o cuatro veces antes de llenarlo; pidámosle café, y observaremos que lo hace en un santiamén, y nos lo sirve en una taza, insospechada en aquella cocina, donde está a la vista todo, excepto, al parecer, las cosas lujosas, reservadas para los actos ceremoniosos. ¿Somos por acaso médicos y salimos de visitar un enfermo? Pues allí, en la cocina, está la moza, esperándonos con todo lo necesario para que lavemos las manos [...] Mas no queremos marchar sin dar antes un vistazo a la casa entera; y ya que hemos notado que en la cocina todo estaba limpio, hasta la barra amarilla del fogón, rúbrica de aquella limpieza, subamos a las habitaciones del piso; vemos que las tablas de castaño o de pino del tillado están cuidadas, que las ropas de las camas demuestran la presencia de la mujer hacendosa, que las paredes, encaladas, ostentan fotografías del interior de un almacén de ropas habanero o ampliaciones fotográficas de los muertos de la familia, y que los muebles son modernos, de bazar. Todo esto nos lo enseña la chica, con su sonrisa "muy siglo XX y muy moderna."73 
Esperamos profundizar más en esta cuestión en futuros trabajos, contrastando estos datos con otras fuentes de la época. No olvidemos, que en este momento además se está fraguando la construcción ideológica de la noción de "hogar" como santuario o lugar de descanso, y espacio femenino por excelencia $^{74}$, si bien habría que ver cómo se traducen estos imaginarios en los espacios rurales tradicionales.

\section{Los nuevos espacios domésticos rurales}

En los años 20-30 del s. XX, la transformación del medio rural en amplias zonas de Asturias es evidente. En la topografía de Soto del Barco (1932), Villalaín sintetiza los cambios en las construcciones y los progresos en la habitabilidad, higiene y confort, que afectan incluso a las viviendas más humildes. En el espacio doméstico, los suelos ya se cubren de tarima de madera, y se abren ventanas amplias y acristaladas. Se introducen las cocinas de hierro de tipo bilbaíno, o se sustituye el fuego en el suelo por fogones elevados con evacuación de humos a través de campana y chimenea. El establo se mantiene en el mismo edificio que la vivienda pero aislado y con una entrada independiente. Como contrapunto, la mayoría de las casas aún carecen de saneamiento y de retretes, pero algunas ya incorporan este cuarto de aseo y pozos negros, donde se retienen las aguas sucias que se aprovechan para el riego. Paulatinamente, las viviendas se van reformando siguiendo el modelo del "labrador acomodado":

"La casa de los labradores acomodados ya es otra cosa: Al entrar en ella, en invierno, vemos que no hay aquel zaguán de terreno resbaladizo, sino un buen piso de morrillo, o de cemento, o de ladrillo. Y si entramos en verano, olerá a cuadra, eso sí, pero no a mugre, ni a eso inconfundible a que huele la desidia, más que la pobreza. Sigamos y vayamos anotando que la cocina está tillada y limpia; que bajo una gran campana ennegrecida por el humo, pero con la pátina disimulada bajo "papeles de cocina", hay dos de éstas: una, la antigua de leña, que sólo se usa para preparar la comida de los animales domésticos, y la otra, de carbón, que es la usada para servicio de las personas. Antiguamente era escaso el número de cocinas de carbón, llamadas "económicas" por el precio del combustible; pero ahora hay medios de transporte más baratos, y además se vende en Soto, y fuera de él, mucho carbón extraído del río y de la playa. [...] Pasemos a la cuadra a ver el ganado, que está almohazado a diario y bien mantenido y lucio. Como aquí no interviene el influjo de la mujer moderna, aun no hay limpieza completa."75

La tendencia general se orienta a la construcción de viviendas de dos plantas, con la cocina y la cuadra en la planta baja y los dormitorios y la sala en la parte alta; la introducción de cocinas de hierro fundido, "económicas", "bilbaínas"; la adquisición de nuevos muebles y enseres de todo tipo, desde aperos de labranza a utensilios de cocina, etc.; así como una mayor preocupación por la limpieza doméstica. En la década de los 30, los cambios ya son irreversibles, y se va fijando en los imaginarios la estampa de la vivienda rural "típica". 

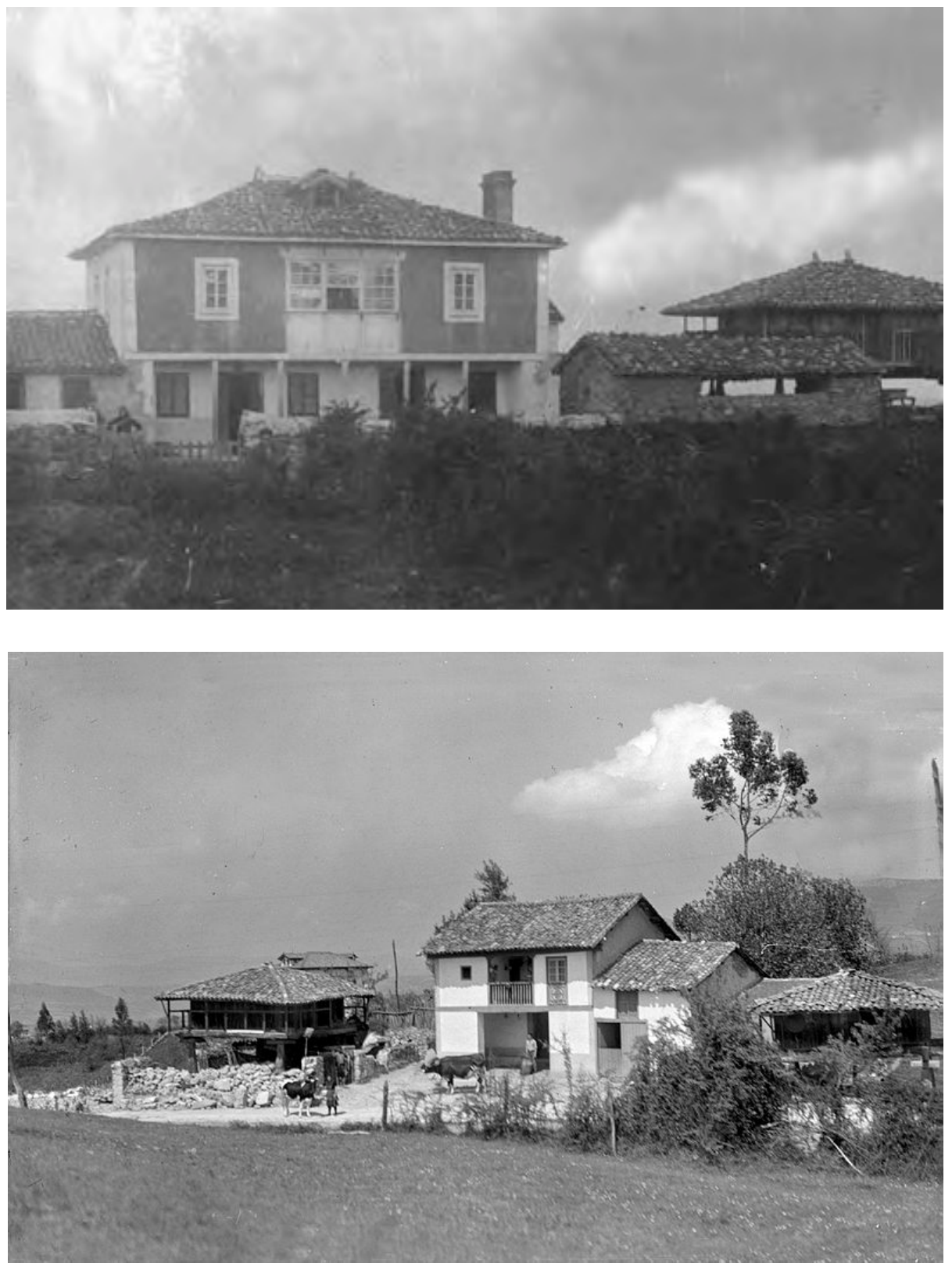

Figs. 4 y 5. Casa en Novellana (Cuideiru), ca. 1919 (Fuente: Florentino Martínez Torner, Las construcciones rurales de Asturias, 191976). Casa tradicional asturiana. Tarjeta postal de Ediciones Alarde, 1960 (Fuente: Muséu del Pueblu d'Asturies). En ambos casos, viviendas de dos plantas, con corredor y galería, revocadas y con ventanales.

En Caravia, por ejemplo, en 1934 la mayor parte de las viviendas ya han sido rehabilitadas y saneadas:

"Casi todas las casas constan de dos pisos y un desván. Suelen estar dotadas en general de buena ventilación y luz directa, con balcones y ventanales amplios, diferenciándose en esto de las que solemos ver por la mayoría de las aldeas de Asturias, en las que si bien no falta el corredor, sin embargo la ventilación suele hacerse por pequeñas ventanas. Casi todos los edificios suelen ser de piedra y ladrillo, si bien existen algunas en los que los tabiques interiores son de madera. Existen en estos pueblos varias casas solariegas que ya van sufriendo transformación, al menos en su interior, 
con el fin de acoplarlas a las exigencias de la vida moderna, aunque también en estos últimos años se vienen construyendo algunas casas con todo confort. En las viviendas de estos lugares se ha desterrado en casi todas ellas la antigua cocina o llar, instalada en el suelo, cambiándola por la moderna de hierro para carbón mineral y leña. Rara es la vivienda que carece de retrete y son raros los pozos negros, ya que en el pueblo de Prado existe una pequeña red de alcantarillado, si bien no se extiende por todas sus calles, y en el de Duesos es frecuente la presencia de grandes sumideros que se sospecha van a desembocar sus aguas al $\operatorname{mar}^{77}$.
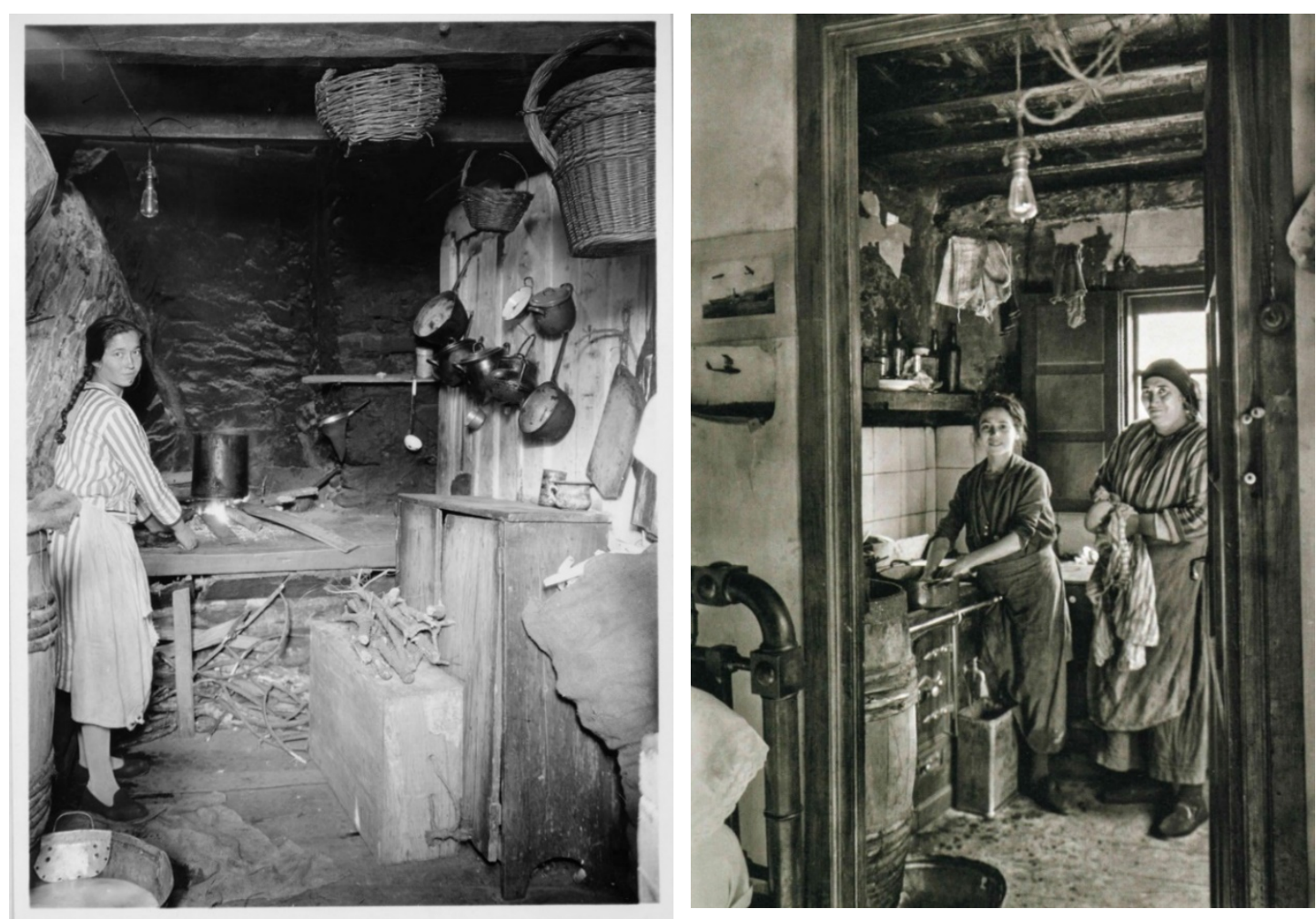

Figs. 6. y 7. Interior de cocinas en la marina asturiana (Cuideiru, 1925). Mientras que en la primera se mantiene el llar alto, en una cocina sencilla y con el menaje a la vista, en la segunda se aprecian ya los cambios. El piso ya está cubierto de losetas, y el frente de cocina con azulejos sanitarios. El llar ha sido sustituido por la "cocina económica". La cocina está iluminada, y se dispone de luz eléctrica. No obstante, sigue existiendo cierta sensación de hacinamiento (véase la cama junto a la puerta). Fuente: Hallazgo de lo ignorado: fotografias de Asturias de Ruth M. Anderson para The Hispanic Society of America, 1925. Catálogo de la exposición.

La topografía de Caso (1945) señala que aunque se conservan casas antiguas (de piedra y sin revoco, cocina de llar pisada de tierra y sin chimenea, y habitaciones grandes sin dividir) se ven pocas. La iniciativa particular y de los indianos retornados han renovado las construcciones. Ahora el tipo medio de vivienda tiene un piso bajo con cocina bilbaína (aunque mantienen la lumbre con chimenea), es grande y espaciosa, posee habitaciones y almacén de aperos y, en el piso superior, dormitorios separados del exterior con una galería, a veces acristalada y con retrete. Esto también afecta al ajuar doméstico y el mobiliario, e indica que en Caso empiezan a verse ciertos lujos en las casas como armarios de luna, cómodas, etc. ${ }^{78}$ No obstante, cabe señalar que en Caso también tuvieron mucha influencia los 
trabajos de reconstrucción realizados por Regiones Devastadas ${ }^{79}$, donde se reedificaron varios pueblos, si bien el médico se sorprende "pues bien a pesar de tener unas casitas magnificas todavía hay quien añora sus casas derruídas, de las que viendo algún ejemplar intacto no tiene uno más remedio que escandalizarse" ${ }^{" 80}$.

No solo los médicos dan cuenta de la transformación del medio rural a finales de siglo. Otros investigadores, como Purificación Viyao (cuyo estudio sobre el oriente de Asturias es una obra pionera de la antropología asturiana) también analizaron los cambios que se habían producido en el periodo de entresiglos. Respecto de la casa, señala que en torno a 1920:

"En armonía con las actuales necesidades ha cambiado el género de construcción en la actualidad, de tal modo que ningún campesino que edifique su casa de nueva planta tiene nada parecido a la antigua, ni en la ribera ni en la montaña. En esta, pocas o ninguna casa moderna deja de tener piso, los dormitorios necesarios y el corredor, cuando no construyen galería, que ya se va generalizando. Conocemos un pueblo de cuarenta y dos vecinos que en el espacio de doce años se han construido trece casas nuevas y se han reformado cinco; todas ellas reúnen excelentes condiciones higiénicas y dan un hermoso aspecto a la aldea." ${ }^{81}$

Los cambios en el ajuar doméstico también se reflejan en las topografías. Aparecen innovaciones en la alimentación, y comienza a ser frecuente el consumo de carne fresca y de aceite, entre otros productos, lo que conlleva el uso de nuevos utensilios y menaje de cocina ${ }^{82}$. Por ejemplo, la popularización del uso de la sartén se testimonia en la topografía de Avilés (1913):

"Antes sólo se comía el pote, y por cierto muy poco substancioso, en la mayoría de las casas de gente del pueblo. Hoy día en casi todas las casas «se tuesta", y lo digo empleando la locución provincial, que quiere decir que todos los días hay sartén al fuego, cosa no usada antes, no siendo en casas acomodadas." 83

O en la de Carreño (1919):

“[...] no exhumaremos los recuerdos de platos regionales hace tiempo desaparecidos, y saludemos al moderno chirrido de las sartenes en las casas pudientes, y al oloroso pote asturiano en las de los pobres." 84

Los viejos enseres de la cocina conviven con los nuevos, pero paulatinamente van desapareciendo. Las ferradas pronto se sustituirán por los cubos de hierro esmaltado, así como los potes de hierro o las calderas de cobre. También están cambiando los patrones de consumo, se populariza el consumo de café, conservas, etc.

Por otra parte, el uso de mobiliario moderno como camas, cómodas, mesitas o armarios se va extendiendo por las aldeas, junto a la generalización de los aparadores, alacenas, mesas y sillas en las salas. En este sentido, resulta significativa la descripción de la decoración de un cuarto en una panera, según la descripción de Villalaín en la topografía de Soto del Barco (1932). En él, se observa la profusión de mobiliario, prueba del incipiente desarrollo de las industrias del mueble locales: 
"Rara vez se duerme en el hórreo de esta clase, pero sí en las paneras, más lujosas, que en nada se diferencian, en cuanto a comodidades, de las casas firmes; y hasta se puede ver en ellas las camas, cuidadas por las mozas de la familia, con sus colchas lujosas; la tulipa de papel picado, que cubre la bombilla eléctrica; los floreros que hay sobre la cómoda; la cubierta, hecha a mano, de la mesita de noche; la alfombra aprisionada por una ruedecilla de la cama en un hueco del tillado carcomido; éste mismo, lustrado con cera en sus partes indemnes; las colondras, empapeladas con suplementos del Diario de la Marina, de La Habana, y fotografías de familia entremezcladas con tarjetas postales, en un portarretratos de pared." 85

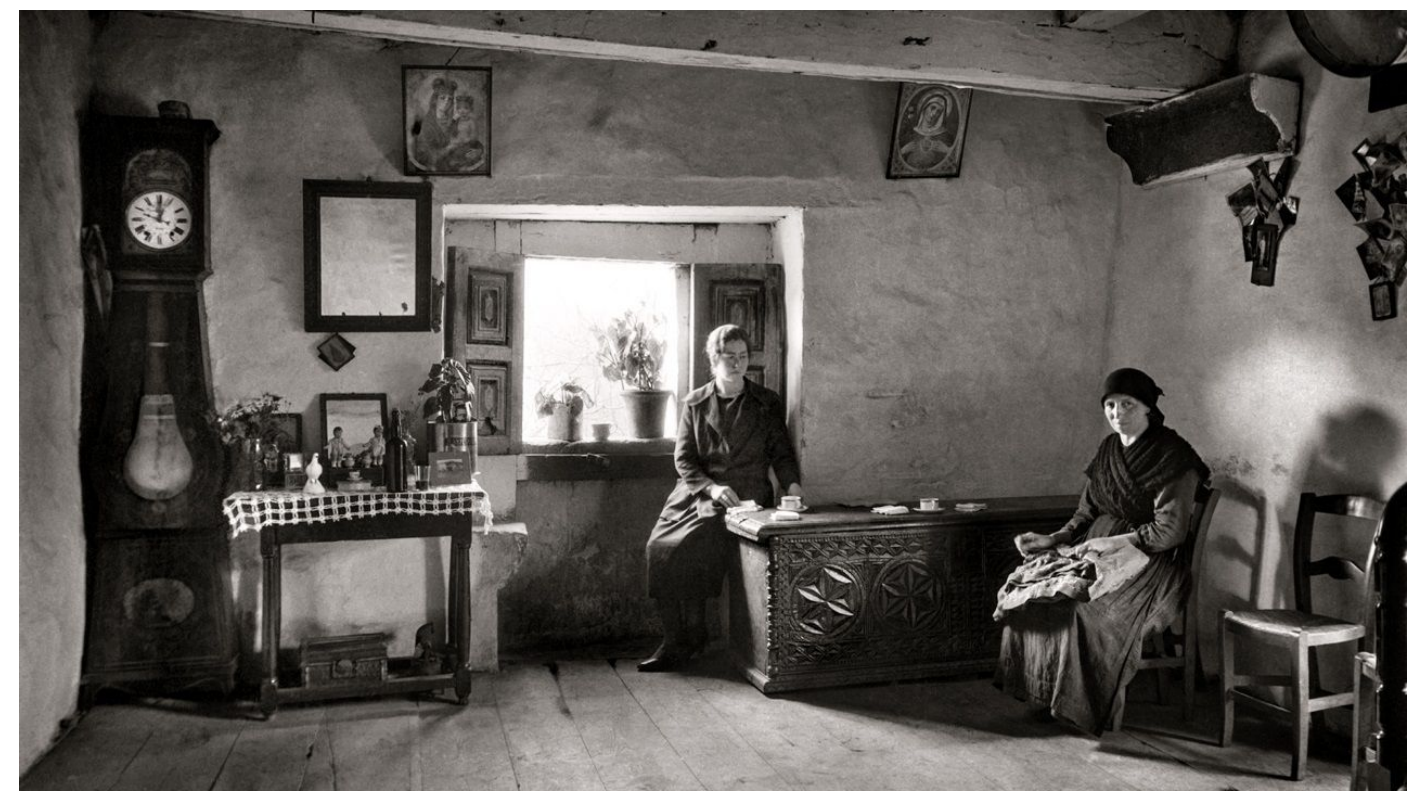

Fig. 8. Villaviciosa, 1925. La foto está tomada en la sala de una vivienda. Se aprecia el contraste entre el viejo mundo rural y el nuevo, la mujer mayor con el traje tradicional, frente a la joven según la moda moderna. Comienzan a combinarse los elementos tradicionales (el suelo de tablones de castaño, el arca, la ventana de madera sin cristales, o el vano, colgado de una viga, que recuerda los usos agrícolas de este espacio) frente a la aparición del encalado de las paredes, el reloj presidiendo la estancia (si bien el reloj es un elemento de prestigio que los campesinos acomodados comienzan a adquirir en la segunda mitad del s. XIX), las estampas religiosas como cuadros decorativos, espejos, las sillas nuevas, y cierto gusto por introducir elementos ornamentales (la mesa pequeña con tapete y diversas figuras y objetos decorativos, o los jarrones con flores y plantas en la ventana). Fuente: Hallazgo de lo ignorado: fotografias de Asturias de Ruth M. Anderson para The Hispanic Society of America, 1925. Catálogo de la exposición

\section{Conclusión}

A diferencia de la etnografía, la literatura o los estudios de arquitectura popular, los profesionales de la medicina aportan una visión más pragmática de la vivienda popular. Con un sentido eminentemente práctico, las topografías analizan las causas de sus problemas y buscan la mejora de la sanidad y la salubridad. No obstante, es preciso tener en cuenta que en la lectura de estos textos se trasluce una mentalidad formada en ambientes urbanos e imbuida de las ideas de progreso social y material, en cierto modo bastante alejada de la visión de los habitantes del medio rural (la sociedad "otra", según García Martínez ${ }^{86}$ ). Su visión es la de un especialista que trabaja en el medio rural y su opinión acerca de este mundo resulta muy sesgada en ocasiones. A pesar de ello, en las topografías se recogen numerosos apuntes 
de carácter etnográfico y lingüístico, y sus testimonios, contrastados con otras fuentes, pueden resultar útiles para analizar la transformación de las viejas casas tradicionales en modernas caserías, así como la introducción de las ideas higienistas en el medio rural, el impacto de la industrialización y las nuevas modas en el espacio doméstico. Una serie de procesos de cambio que arrancan a finales del siglo XIX, y que llegan a nuestros días, con los matices de los contextos de las diferentes comarcas asturianas ${ }^{87}$.

\section{NOTAS}

${ }^{1}$ Una buena síntesis de los estudios sobre vivienda obrera en España en Luis Arias González, El socialismo y la vivienda obrera en España (1926-1939). La cooperativa socialista de casas baratas "Pablo Iglesias”. (Salamanca: Ediciones Universidad de Salamanca, 2003). Un balance más reciente, en María del Mar Díaz González, "Los alojamientos para trabajadores asturianos en la acción social de los ricos con los pobres y su política paternalista (1861-1970)," Santander. Estudios de Patrimonio, no. 3 (2020): 189-232, https://santanderestudiospatrimonio.unican.es/index.php/sanespat/article/view/48.

2 A este respecto, resultan interesantes los trabajos de Isabel Ordieres Díez, La Vivienda rural en Cantabria: un estudio durante la autarquía (Santander: Ikono, 1998) y de José Luis Oyón Bañales, "Colonias agrícolas y poblados de colonización. Arquitectura y vivienda rural en España (1850-1965)," (Tesis doctoral, Universitat Politècnica de Catalunya, 1985), https://www.tesisenred.net/handle/10803/5863\#page=5.

3 Xuan Fernández Bas, “Las topografías médicas en Asturias,” en Topografía médica de Gijón (1918), de Felipe Portolá Puyos, eds. Xuan Fernández Bas y Francisco Prendes Quirós (Gijón: VTP, 2004), 9.

${ }^{4}$ Germán Ojeda, Biografía contemporánea de Asturias. Condiciones de vida en la región en torno a la primera mitad del siglo XX. Estudio basado en las topografías médicas de los municipios asturianos (Oviedo: Cajastur, 2006), 28.

5 Luis Urteaga, "Miseria, miasmas y microbios. Las topografías médicas y el estudio del medio ambiente en el siglo XIX", Cuadernos Críticos de Geografia Humana V, no. 29, http://www.ub.edu/geocrit/geo29.htm; Juan Casco Solís, "Las topografías médicas. Revisión y cronología," Asclepio: Revista de historia de la medicina y de la ciencia 53, no. 1 (2001): 213-44, https://doi.org/10.3989/asclepio.2001.v53.i1.178.

${ }_{6}$ Para un análisis más pormenorizado de las topografías en Asturias, Fernández Bas ha publicado un estudio introductorio sobre la cuestión con abundantes referencias y un catálogo de las topografías médicas referidas al territorio asturiano, en su estudio introductorio a la reedición de la topografía médica de Gijón (Fernández Bas, "Las topografías médicas en Asturias"), señalando los inventarios realizados en otros trabajos.

${ }^{7}$ Higinio del Campo, "Estudios sobre la pelagra," Boletín de Medicina, Cirugía y Farmacia, no. 97 (7 de noviembre de 1847): 363-66, http://hemerotecadigital.bne.es/details.vm?q=parent\%3A0003027985\&lang=es\&s=592. Sobre su vida y obra, Víctor Manuel Álvarez Antuña, "Asturias y los asturianos en la obra médica de Higinio del Campo (1808 - 1885)," Boletín del Real Instituto de Estudios Asturianos 52, no. 152 (1998): 51-74, https://bibliotecavirtual.asturias.es/i18n/publicaciones/numeros_por_mes.cmd?idPublicacion=24855\&a nyo $=1998$.

8 Ojeda, Biografía contemporánea de Asturias.

9 Francisco Feo Parrondo, "Geografía Médica del Concejo asturiano de Carreño," Polígonos. Revista de Geografia, no. 7 (27 de febrero de 2014): 9-28, http://dx.doi.org/10.18002/pol.v0i7.1047.

${ }^{10}$ Luis Vicente Sánchez Fernández, Juan Carlos Cobo Barquín, y Radhamés Hernández Mejía, "Ambiente y enfermedad en Asturias durante la Restauración. Estudio de las topografías médicas," Revista de Demografia Histórica 34, no. 2 (2016): 161-92, http://digibuo.uniovi.es/dspace/handle/10651/51659.

11 Sonia García Galán, "De las prácticas tradicionales a la supervisión médica en el ejercicio de la maternidad. Asturias 1900-1931," Dynamis: Acta Hispanica ad Medicinae Scientiarumque. Historiam Illustrandam 31, no. 1 (2011): 0131-57, https://doi.org/10.4321/S0211-95362011000100007.

12 Manuel Gutiérrez Claverol y José Carlos García Ramos, "La geología de Asturias a través de las Topografías Médicas," Trabajos de geología, no. $36 \quad$ (2016): 203-36, http://geol00.geol.uniovi.es/TDG/Volumen36/TG36-12.PDF. 
${ }^{13}$ Luis Vicente Sánchez Fernández et al., "Condiciones de vida en las cuencas mineras centrales de Asturias durante la fase expansiva de la revolución industrial asturiana (1885-1907) a través de las Topografías Médicas," Ería 3, no. 3 (20 de noviembre de 2018): 367-84, https://doi.org/10.17811/er.3.2018.367-384.

14 Juan Fernán Pérez, "Topografía médica del concejo de Nava (Asturias)," (Inédito, documento mecanografiado, 1931), 21, http://bibliotecavirtual.ranm.es/ranm/es/consulta/registro.cmd?id=81.

15 Según el trabajo realizado por Fernández Bas, "Las topografías médicas en Asturias," 13, se contabilizan al menos 51, aunque no se descarta que haya más.

16 Ojeda, Biografía contemporánea de Asturias, 35. Hemos revisado 47 de las 51 inventariadas, pero hay que señalar que no todas ofrecen datos acerca de la vivienda rural y, en las que sí se aportan noticias, la calidad es muy variable. Cabría destacar las realizadas por los médicos José de Villalaín, Felipe Portolá Puyos o las de Jove y Canella. Sobre las topografías, y complementando las observaciones realizadas por Germán Ojeda, hay que indicar que en la de Castropol (1946), el apartado dedicado a la vivienda está reelaborado a partir de textos de otras topografías (probablemente los trabajos de Villalaín), y resulta inverosímil porque las descripciones de hórreos de corredor y viviendas cubiertas de teja no encajan en absoluto en la arquitectura de pizarra del extremo occidental, donde predominan los cabazos. Tampoco los vocablos usados (llar, cucho, etc.), propios del asturiano, responden al léxico del gallego local. En otros casos, los nuevos trabajos toman como referencia los ya publicados, y parafrasean párrafos, aunque sin citar. Por ejemplo, la descripción de los enseres de la casa tradicional de Caso (p. 32), está sin duda inspirada en la misma descripción de la de Sobrescobio (p. 39). También observamos que la topografía de Cangas de Onís, es prácticamente copia de la de Cabrales (probablemente ambas son del mismo autor). 17 Arias González, El socialismo y la vivienda obrera en España (1926-1939), 31-34.

18 Alfonso Muñoz Cosme, "Un siglo de investigación sobre la arquitectura tradicional en España," Patrimonio Cultural de España, no. 8 (2014): 21-42, https://doi.org/10.4438/030-14-182-4. Almarcha Núñez-Herrador, "El descubrimiento y la puesta en valor de la arquitectura popular: de Fernando García Mercadal a Luis Feduchi," en Lecciones de los maestros: aproximación histórico-crítica a los grandes historiadores de la arquitectura española. Seminario celebrado en Zaragoza los días 26, 27 y 28 de noviembre de 2009 (Zaragoza: Institución «Fernando el Católico»; Universidad de Zaragoza), 185-202. https://ifc.dpz.es/publicaciones/ebooks/id/3129

19 Para más información sobre esta cuestión, puede consultarse: Xuan F. Bas Costales, "Estudio preliminar. Los estudios etnográficos de Purificación Viyao y Romualda Martín-Ayuso," en Dos estudios etnográficos sobre el oriente de Asturias, (Gijón: Muséu del Pueblu d'Asturies, 2007), 9-23.; Juaco López Álvarez, "Antonio Machado Álvarez, Eugenio de Olavarría, Rosa Fernández y su Contribución al folklore de Asturias," en Contribución al folk-lore de Asturias. Folk-lore de Proaza. Notas y apuntes recogidos y ordenados por L. Giner Arivau (Gijón: Muséu del Pueblu d'Asturies; FM de CE y UP. Ayto de Gijón/Xixón; Red de Museos Etnográficos de Asturias, 2009), 12-42, https://www.gijon.es/from/5659/publicacions/show/4277-folk-lore-de-proaza-contribucion-al-folk-lorede-asturias; José Luis Pérez de Castro, Los estudios de folklore en Asturias (Salinas, Asturias: Ayalga Ediciones, 1984).

20 Florentino Martínez Torner, Dos estudios geográficos y etnográficos sobre Asturias (Quirós: Museo Etnográfico de Quirós, 2005), http://www.redmeda.com/biblioteca-digital.; María de la Purificación Viyao Valdés y Romualda Martín-Ayuso, Dos estudios etnográficos sobre el oriente de Asturias (19201921) (Gijón: Muséu del Pueblu d’Asturies, 2007).

21 Arias González, El socialismo y la vivienda obrera en España (1926-1939), 37.

22 Lily Litvak, El tiempo de los trenes. El paisaje español en el arte y la literatura del realismo (1849-1918) (Barcelona: Ediciones del Serbal, 1991).

23 Arias González, El socialismo y la vivienda obrera en España (1926-1939), 37.

24 Arias González, 37.

25 Campo, "Estudios sobre la pelagra," 364. Citado en Álvarez Antuña, “Asturias y los asturianos en la obra médica de Higinio del Campo (1808 - 1885)," 65.

26 Nicanor Muñiz Prada, Apuntes para la topografia médica del concejo de Mieres y de su comarca minera (Oviedo: Imprenta del Hospicio Provincial, 1885), 36-37, https://bvpb.mcu.es/es/consulta/resultados_ocr.do?id=33622\&forma=ficha\&tipoResultados=BIB\&posic ion=1.

27 José María Jove Canella, “Topografía médica de Laviana,” (inédito, documento manuscrito, 1927), 102, http://bibliotecavirtual.ranm.es/ranm/i18n/consulta/registro.cmd?id=38.

28 Joaquín Vilar Ferrán, Topografia médica del concejo de Cabrales (Madrid: Establecimiento Tipográfico de "El Liberal", 1921), 262. 
29 José María Jove Canella y Luis Alonso, Topografia Médica del término municipal de Sobrescobio (Madrid: Imprenta y Encuadernación de Julio Cosano, 1932), 39, http://bibliotecavirtual.ranm.es/ranm/es/consulta/resultados_ocr.cmd?buscar_cabecera=Buscar\&id=346 $5 \&$ tipoResultados $=$ BIB\&posicion $=1 \&$ forma $=$ ficha .

30 Francisco Pérez Gómez, "Topografía médica del concejo de Caso," (inédito, documento mecanografiado, 1945), 62, http://bibliotecavirtual.ranm.es/ranm/es/consulta/registro.cmd?id=86

31 Anónimo, "Topografía médica del Concejo de Lena (Oviedo)," (inédito, documento manuscrito, 1907), 55, http://bibliotecavirtual.ranm.es/ranm/i18n/consulta/registro.cmd?id=1191.

32 José de Villalaín Fernández, "Topografía médica de Avilés," Anales de la Real Academia de Medicina, 33 (1913): 273, http://bibliotecavirtual.ranm.es/ranm/es/consulta/registro.cmd?id=338.

33 Vilar Ferrán, Topografía médica del concejo de Cabrales, 262.

${ }^{34}$ Felipe Portolá Puyós, Topografía médica del concejo de Gijón (Madrid: Establecimiento tipográfico de "El Liberal", 1918), 127, https://bvpb.mcu.es/es/consulta/resultados_ocr.do?id=31826\&forma=ficha\&tipoResultados=BIB\&posic ion $=7$.

35 Valentín Fernández Fernández, Topografía Médica del Concejo de Tapia de Casariego (Madrid: Imprenta y Encuadernación de Julio Cosano, 1932), 11, http://bibliotecavirtual.ranm.es/ranm/i18n/consulta/registro.cmd?id=331.

${ }^{36}$ Felipe Portolá Puyós, Topografia médica del concejo de Ponga (Madrid: Est. Tip. de los hijos de Tello, 1915), 63, http://bibliotecavirtual.ranm.es/ranm/es/consulta/registro.cmd?id=242.

37 Anónimo, "Topografía médica del Concejo de Lena (Oviedo)," 55.

38 Anónimo, "Topografía médica del concejo de Cangas de Onís," (inédito, documento mecanografiado, 1934), 69, http://bibliotecavirtual.ranm.es/ranm/i18n/consulta/registro.cmd?id=82.

${ }^{39}$ Portolá Puyós, Topografía médica del concejo de Ponga, 127 y 131.

${ }^{40}$ Pedro Felipe Monlau, Higiene industrial. ¿Qué medidas higiénicas puede dictar el gobierno á favor de las clases obreras? Memoria (Madrid: Imprenta y Estereotipia de M. Rivadeneyra, 1856).

${ }^{41}$ Nicanor Muñiz Prada, Nociones de higiene con aplicación a los mineros de hulla. Lecciones dadas en la Escuela de Capataces de Minas, Hornos y Máquinas de Mieres (Oviedo: Imp. de Flórez Pintado y Comp., 1885), 71-83, http://hdl.handle.net/10651/36684.

42 Ambrosio Rodríguez y Rodríguez, Higiene popular. Contribución al estudio de la higiene de los trabajadores y enfermedades de los jornaleros (Gijón: Tip. La Industria, 1903).

${ }^{43}$ José Úbeda y Correal, El Presupuesto de una familia obrera (Madrid: Establecimiento tipográfico de E. Teodoro, 1902), https://ddd.uab.cat/record/84808.

${ }_{44}$ Aurelio de Llano Roza de Ampudia, Hogar y patria (Oviedo: Imprenta La Comercial, 1906), https://bibliotecavirtual.asturias.es/i18n/consulta/registro.cmd?id=430.

45 Francisco Gómez de Membrillera, "Saneamiento e higienización de España. Memoria presentada al concurso de la asociación de ingenieros civiles," Revista de obras públicas 1 (1920): 317-32, http://ropdigital.ciccp.es/detalle_articulo.php?registro=14178\&anio=1920\&numero_revista $=2$

36. Citada en Luis Vicente Sánchez Fernández y Rolando Hugo Neri Vela, eds., "Introducción," en Geografia médica del concejo de Bimenes (Oviedo), 1907 (Bimenes: Ayuntamiento de Bimenes, 2016), 30.

${ }^{46}$ Vilar Ferrán, Topografia médica del concejo de Cabrales, 292. Se proponen medidas similares en otras topografías, como la de Ponga, Piloña, etc.

47 Por ejemplo, en Anónimo, "Topografía médica del concejo de Caravia," (inédito, documento mecanografiado, 1934), 45, http://bibliotecavirtual.ranm.es/ranm/es/consulta/registro.cmd?id=90, o en Portolá Puyós, Topografía médica del concejo de Ponga, 181-83.

48 Juaco López Álvarez, "Clarín, los campesinos y el 'Folk-Lore Asturiano'," en Clarín y su tiempo. Exposición conmemorativa del centenario de la muerte de Leopoldo Alas (1901-2001), ed. Javier Barón Thaidigsmann (Oviedo: Cajastur; Fundación Ramón Areces, 2001), 58, http://s3.redmeda.com/biblioteca/lopez_2001_clarin.pdf.

49 José de Villalaín Fernández, "Topografía médica del concejo de Carreño," (inédito, documento manuscrito,

1919), http://bibliotecavirtual.ranm.es/ranm/i18n/consulta/registro.cmd?control=RANMB20130004815.

${ }^{50}$ Fernando García Valdés, Topografía Médica del Concejo de Oviedo (Madrid: Est. Tip de la viuda e hijos de Tello, 1911), 92-93, https://www.europeana.eu/en/item/2022705/lod_oai_bibliotecavirtual_ranm_es_333_ent1.

${ }^{51}$ López Álvarez, "Clarín, los campesinos y el 'Folk-Lore Asturiano',", 58. 
52 Anónimo, "Geografía médica del Concejo de Bimenes," (documento manuscrito, 1907), 37-38, http://bibliotecavirtual.ranm.es/ranm/i18n/consulta/registro.cmd?id=74.

53 Villalaín Fernández, "Topografía médica de Avilés," 276.

54 Anónimo, “Geografía médica de Degaña," (inédito, documento manuscrito 1913), 21, http://bibliotecavirtual.ranm.es/ranm/i18n/consulta/registro.cmd?id=101.

55 Fernández Fernández, Topografía Médica del Concejo de Tapia de Casariego, 32.

56 Fernández Fernández, 57.

57 Fernández Fernández, 55.

58 España. Dirección General de la Producción Agraria. Ministerio de Economía nacional, Contribución al estudio de la casa rural (Madrid: Ministerio de Economía Nacional; Dirección General de Agricultura, 1929).

59 Oyón Bañales, “Colonias agrícolas y poblados de colonización. Arquitectura y vivienda rural en España (1850-1965)," 198.

60 Vilar Ferrán, Topografía médica del concejo de Cabrales, 155.

${ }^{61}$ López Álvarez, "Clarín, los campesinos y el 'Folk-Lore Asturiano'," 60.

62 Francisco Xosé Fernández Riestra y Jesús Marcos Fernández, Aproximación a la arquitectura tradicional de los concejos de Cangas del Narcea, Ibias y Degaña (Asturias) (Cangas del Narcea: GDR Alto Narcea Muniellos, 2011), 90, https://issuu.com/balcondemuniellos/docs/arquitectura_tradicional.

63 Villalaín Fernández, "Topografía médica de Avilés," 276.

64 Villalaín Fernández, 108.

65 Villalaín Fernández, 108.

66 Villalaín Fernández, “Topografía médica del concejo de Carreño,” 79.

67 Villalaín Fernández, 115.

68 Gloria Franco Rubio, "La vivienda en el Antiguo Régimen: de espacio habitable a espacio social," Chronica Nova, no. 35 (2009): 63-103, http://hdl.handle.net/10481/22521.

69 Beatriz Blasco Esquivias, La casa: evolución del espacio doméstico en España (Madrid: El Viso, 2006).

70 José de Villalaín Fernández, Topografia médica del concejo de Corvera de Asturias (Madrid: Imp. de la Ciudad Lineal, 1925), 70, http://bibliotecavirtual.ranm.es/ranm/es/consulta/registro.cmd?id=329.

71 Villalaín Fernández, 69.

72 Villalaín Fernández, 70.

73 José de Villalaín Fernández, Toponimia médica del concejo de Soto del Barco (Madrid: Imprenta y $\begin{array}{lllll}\text { Encuadernación de Julio } & \text { Cosano, }\end{array}$ http://bibliotecavirtual.ranm.es/ranm/es/consulta/registro.cmd?id=332.

${ }^{74}$ Sandra Ezquerra Samper, "Dentro y fuera. De lo doméstico. De lo público," en Catálogo de la Exposición Doméstic, ed. Roger Canals (Barcelona: The Private Space and Photographic Social Vision, 2010), 2, https://www.photographicsocialvision.org/domestic/pdf/sandra_ezquerra_cast.pdf.

75 Villalaín Fernández, Toponimia médica del concejo de Soto del Barco, 76-80.

76 Martínez Torner, Dos estudios geográficos y etnográficos sobre Asturias, fig. 27.

77 Anónimo, "Topografía médica del concejo de Caravia," 21.

78 Pérez Gómez, "Topografía médica del concejo de Caso," 32.

79 Miriam Andrés Eguiburu, "La reconquista del paisaje arquitectónico. Los 'pueblos adoptados' en Asturias," De arte: revista de Historia del Arte, n. ${ }^{\circ} 14$ (2015): 181-95, http://dx.doi.org/10.18002/da.v0i14.1656.

80 Pérez Gómez, "Topografía médica del concejo de Caso," 64.

81 Viyao Valdés y Martín-Ayuso, Dos estudios etnográficos sobre el oriente de Asturias (1920-1921), 77.

82 Juaco López Álvarez et al., Los asturianos na cocina. La vida doméstica n’Asturies, 1800-1965 / Los asturianos en la cocina. La vida doméstica en Asturias, 1800-1965. Catálogo de la exposición (Gijón: Muséu del Pueblu d'Asturies; FMCE y UP; Ayto. de Gijón, 2005), http://www.gijon.es/publicacions/show/4256-los-asturianos-en-la-cocina-la-vida-domestica-en-asturias1800-1965/.

83 Villalaín Fernández, "Topografía médica de Avilés," 245.

84 Villalaín Fernández, "Topografía médica del concejo de Carreño,” 84.

85 Villalaín Fernández, Toponimia médica del concejo de Soto del Barco, 85.

86 Adolfo García Martínez, Antropología de Asturias. I. La cultura tradicional, patrimonio de futuro, (Oviedo: KRK, 2008), 416. 
87 David González-Álvarez y Pablo Alonso González, "Casas y cambio cultural: metodología interdisciplinar para el estudio del espacio construido en la España rural contemporánea," Arqueología de la Arquitectura, no. 16 (2019), https://doi.org/10.3989/arq.arqt.2019.007.

Fecha de recepción: 5 de enero de 2021

Fecha de revisión: 24 de enero de 2021

Fecha de aceptación: 3 de febrero de 2021 